Proximal humeral fracture osteosynthesis in Belgium: a retrospective population-based epidemiologic study

\author{
Jan Dauwe ${ }^{* 1,2}$, Carolin Danker ${ }^{1}$, Michiel Herteleer ${ }^{3}$, Kris Vanhaecht ${ }^{4}$, Stefaan Nijs ${ }^{3}$
}

1 AO Research Institute Davos, Davos, Switzerland

2 Department of Orthopaedic Surgery, University Hospitals Leuven, Belgium

3 Department of Trauma Surgery, University Hospitals Leuven, Belgium

4 LIHP, Leuven Institute for Healthcare Policy, Leuven, Belgium

*Corresponding author

Jan Dauwe MD, MSc

University Hospitals Leuven

Herestraat 49, 3000 Leuven, Belgium

E-mail: dauwejan@gmail.com 


\title{
Proximal humeral fracture osteosynthesis in Belgium: a retrospective population-based epidemiologic study
}

\begin{abstract}
Purpose: Proximal humeral fractures (PHF) comprise approximately five percent of all fractures and this percentage will continue to increase due to the aging population with accompanying osteoporosis. Most PHF can be treated conservatively, however, in displaced fractures, surgical treatment is recommended. Retrospective analyses of large groups or even populations are important as they can contribute to the needs of the community. The aim of this study was to assess the epidemiology and management of PHF fixation in Belgium based on the most recently available data from the last five years.

Methods: The governmental organization National Institute of Health and Disability Insurance provided a population-based database with all PHF treated surgically or nonoperatively. This database was retrospectively assessed. The data included age, sex, region of residence, year and treatment strategy for every patient. Healthcare expenses were also provided.

Results: A total of 62,290 PHF were identified in Belgium between 2014-2018. The incidence was 111 per 100,000 persons/year. The highest incidence was observed in females and people older than 80 years. The average proportion of osteosynthesis was calculated at $21 \%$. The Belgian government spent on average more than two million euros each year on PHF treatment.

Conclusion: The overall incidence of PHF increased by $12 \%$ over the last five years. The majority were treated nonoperatively in Belgium.
\end{abstract}

Keywords: Proximal humerus; Fracture; Epidemiology; Belgium; Healthcare 


\section{Introduction}

According to the most recent data from 2018, Belgium is number nine on the list of OECD (Organization for Economic Co-Operation and Development) countries, spending 10.4\% of their GDP (Gross Domestic Product) on healthcare expenses [1]. Musculoskeletal conditions (including trauma) are the most common causes of physical disability and represent an enormous socio-economic cost [2]. Proximal humeral fractures (PHF) currently account for approximately five percent of all fractures [3] with an incidence of approximately 66$83 / 100,000$ person/year worldwide [4-7]. The incidence increases in both male and female patients older than 50 years but escalates four times faster in women. The highest incidence is found in women aged 80-89 years old. These trends were not only present in Europe, but also in the United States $[8,9]$. The number of PHF will continue to increase due to the aging population with accompanying osteoporosis. [10]. Most of the PHF can be treated conservatively [11-13], however, in displaced fractures surgical treatment is recommended [14]. Surgical management of PHF consists of osteosynthesis when possible. Nevertheless, especially in the elderly population, joint replacement using reversed shoulder arthroplasty (RSA) is a valid treatment option [15]. Medical literature does not provide a consensus on PHF treatment for more complex cases. Therefore, retrospective analyses of large groups or even populations are useful and important. Epidemiologic research can contribute to the needs of the community and is helpful in planning the provision of trauma related healthcare [16,17].

The aim of this study was to assess the epidemiology and management of PHF fixation in Belgium based on the most recently available data. In the present paper, we reported the incidence, treatment strategies, and demographic distribution of PHF osteosynthesis over time. Furthermore, an evaluation of healthcare resource expenses was performed of the last five years. 


\section{Materials and Methods}

\section{$\underline{\text { Data retrieval }}$}

The Belgian governmental organization of RIZIV-INAMI (Rijksinstituut voor Ziekte en Invaliditeitsverzekering-Institut national d'assurance maladie-invalidité) or Belgian National Institute for Health and Disability Insurance (NIHDI) systematically collects all data linked to NIHDI nomenclature numbers [18]. These nomenclature numbers or codes officially represent a medical diagnosis, treatment and reimbursement rate. Furthermore, all treating physicians are strictly obligated to register these nomenclature numbers. This large national electronic database was retrospectively consulted for every number linked to a PHF in the time span of 2014-2018. In 2014, the nomenclature list for operative procedures was restructured; sorting fractures by treatment strategy instead of anatomy-based categories. Therefore, only data from the last five years of the national database is used in this project. The numbers are linked to the age and gender of the patient, the year of the procedure and the region of residence. The reimbursement per nomenclature number was also recorded in the database. This is the money (euros) which is reimbursed by the government and is fixed per nomenclature number. The data did not allow for the identification of patients who had multiple or recurrent PHF, since no nomenclature number exists for revision surgery in PHF treatment. Ethics committee approval was not necessary for this study since no connection to the individual patient existed and no patient record with personal medical information could be reviewed.

After reviewing the nomenclature list for orthopaedic and trauma surgery, seven nomenclature numbers were linked to PHF: 296811-296822 (conservative treatment of fractures of the humeral head or neck without reposition), 296214-296225 (conservative treatment of a luxation and fracture of the shoulder with reposition), 296236-296240 (conservative treatment of a fracture of the humeral head or neck with reposition), 275332275343 (percutaneous pinning of a fracture or fracture-luxation of the upper end of the humerus), 275354275365 (open reduction and osteosynthesis of a fracture of the tuberosities of the humeral head), 275376275380 (open reduction and osteosynthesis of a fracture or fracture-luxation of the humeral head or neck). The number for surgical treatment via arthroplasty (total, hemi or reversed) was excluded since the database did not distinguish between a fracture indication or non-fracture indication. Therefore, sensitive patient data would be required and was not accessible in the national database. In addition, the nomenclature number for surgical treatment of non-union fractures and osteotomy of the humerus were also excluded because there was no difference between anatomical location (proximal-diaphyseal-distal). 
$\underline{\text { Data management and calculations }}$

The incidence of PHF per 100,000 persons/year was calculated by dividing the number of PHF by the number of Belgian inhabitants per year and multiplying by 100,000 . The incidence was calculated for different parameters (year, age and geographic region). Belgium can be divided into three main regions: Flanders, Wallonia and Brussels representing circa six million, circa four million and approximately one million inhabitants respectively [17]. Correct Belgian population data was provided through STATBEL [19]. The proportion or ratio PHF treated surgically (with osteosynthesis) was defined as the number of PHF surgically treated relative to all PHF cases. Healthcare expenses for PHF in Belgium were reported and analysed over a time span of five years. The expenses (or reimbursement fee) per fracture were calculated by dividing the total number of cases by the total expenses for every year. 


\section{Results}

\section{Fracture incidence}

A total number of 62,290 PHF were diagnosed in a 5-year period from 2014-2018. The average incidence was 111 per 100,000 persons/year. The incidence has increased by 12\% (from 102 per 100,000 persons/year to 114 per 100,000 persons/year) (Fig. 1).

Moreover, this graph shows a notably higher incidence among women (150 per 100,000 persons/year in comparison to men (72 per 100,000 persons/year). A relative higher increase was observed in females compared to males $13 \%$ and $11 \%$ respectively. Overall, sixty-nine percent of all patients to be diagnosed, were female (42,813 diagnoses) and thirty-one percent male (19,477 diagnoses). When grouping the total incidence according to age clusters, two peaks were observed. The first small peak is present in the age group 10-19 years. The fracture incidence increase starts significantly at circa 50 years old and a steep increase is documented starting from between 70-79 years old (Fig. 2). The incidence increased in all three regions in Belgium between 2014 and 2018 (Fig. 3). However, in Brussels, the overall incidence was noticeably lower compared to the other two regions and to the total incidence.

\section{Proportion of surgery (osteosynthesis)}

Between 2014 and 2018, 13,154 fractures (21\%) were treated operatively. The proportion of patients who underwent surgery was similar for female patients compared to male patients, $21 \%$ and $23 \%$ respectively. Over the 5-year period, the overall proportion of fracture fixation remained roughly constant at between $19 \%$ and $23 \%$. The proportion of patients undergoing surgery varied between age groups. The lowest percentage of patients who underwent surgery was those between the ages of 0 and 9 years $(5 \%)$. The proportion of patients undergoing surgery increased gradually until the age category 50 to 59 years, to a maximum of $28 \%$ (Fig 2).

\section{$\underline{\text { Surgical treatment }}$}

Surgical strategies included were; percutaneous pinning of a PHF, open reduction and osteosynthesis of fracture of the tuberosities, open reduction and osteosynthesis of fracture or fracture-luxation of the humeral head or neck. These categories were restructured into two main categories: percutaneous pinning (PP) and open reduction internal fixation (ORIF). Percutaneous pinning treatment of PHF accounted only for 655 fractures in our cohort from 2014 to 2018 . 
The choice of surgical treatment differs between age groups (Fig. 4). ORIF was the overall key treatment method. Percutaneous pinning, however, was the main treatment option in ages 0-9 years, followed by ages 10-19 years.

\section{Healthcare expenses}

The total healthcare expenses (or reimbursement fee for the patient) were provided per nomenclature number. From 2014-2018 an average of 2,062,594 euros were spent per year on PHF treatment. The total reimbursement fee per fracture per year is 166 euros on average and has remained constant. The reimbursement fee for operative treatment is approximately four times higher than for nonoperative treatment (Fig. 5). 


\section{Discussion}

The purpose of this study was to assess the epidemiology and management of proximal humeral fracture (PHF) fixation in Belgium based on the most recently available data from the last five years (2014- 2018).

The incidence of PHF generally shows a small first peak in children between 10-14 years and is highest in the elderly between 75-90 years of age [20]. Exactly the same curve morphology was found in the current study and presented in figure 2. In the current study, an incidence of 111 per 100,000 persons/year was calculated for the whole of the Belgian population. This finding is considerably higher than in some other studies; 83 per 100,000 persons/year found in Tampere for example [6]. Tampere is described as a mid-sized town in Southern Finland with a population of approximately 220,000 , whereas our data was based on the whole Belgian population of 11.4 million inhabitants [19]. With an incidence of 532 per 100,000 persons/year the highest number of PHF was found in age group older than 80 years (Fig. 2). This is somewhat higher than 502/100,000 persons/year in Denmark for the same age group [6,21]. Over the last five years the incidence was higher in females every year (Fig. 1) compared to men, indicating that women are circa two times more affected than male patients. Taking Belgium's different regions into account, a lower PHF incidence was documented in the capital region of Brussels (Fig. 3). This finding can be easily explained since $87 \%$ of the inhabitants in Brussels are younger than 65 years old [19].

In this study, an average $21 \%$ of patients underwent osteosynthesis. This is considerably higher compared to existing North American literature where a proportion of circa 15\% is reported [11-13]. That said, our result is more than three times lower than that of Katthagen et al., [22] where in a study of 423 patients, $77 \%$ of those older than 18 years underwent surgery. Nevertheless, epidemiological investigation showed that $80 \%$ of PHF were not displaced or minimally displaced [9]. Systematic reviews and meta-analysis still report the possibility and benefit of nonoperative treatment for PHF [23,24].

The highest proportion of PHF fixation (28\%) was found in patients aged between 50 and 59 years, closely followed by age group 60-69 years (Fig 2). Regarding surgical strategies for PHF treatment, Floyd et al.[13] reported the percentage of patients receiving surgery as $15.4 \%$ in the United States of America using data from 2011. In that study, the most likely age group to receive surgical treatment was $66-79$ years. This is approximately one age cluster older compared to the findings in our study. An explanation for this contrasting result could lie in the fact that in our study, only the proportion of patients undergoing fracture fixation was considered, whereas Floyd et al. [13] included ORIF, hemi-arthroplasty (HA) and reversed shoulder arthroplasty 
(RSA). Joint replacement surgery for PHF is typically performed for complex fractures and in the elderly population since the postoperative complication rate increases with age independent of internal fixation type [15]. In the United States, twenty-two percent of the PHF were treated with HA whereas open reduction internal fixation was performed three times more often (66\%) [13]. Circa twelve percent was treated with primary RSA [13]. Nevertheless, other studies recommended RSA in favour of HA for complex PHF in elderly patients based on clinical outcome $[15,25]$.

The current population-based study allowed us to analyse a high number of PHF, however, there are some limitations. The data provided did not allow the identification of patients who had multiple or recurrent PHF. Furthermore, shoulder arthroplasty (HA or RSA) was not included since the database of RIZIV-INAMI did not distinguish between a fracture indication or non-fracture indication. We recognize that the lack of reliable data on shoulder arthroplasty is relevant and this is the main weakness of this epidemiological study. Yet, these limitations are inherent to the information from the national database. Inaccessible sensitive patient data would be required to solve this problem. Furthermore, other studies focusing on the epidemiology of PHF have been reported, however, this study also includes valuable data about paediatric fractures.

In conclusion, 62,290 proximal humeral fractures were evaluated. The overall incidence of PHF increased by $12 \%$ over the last five years. The highest incidence was observed in females and in patients over 80 years which is consistent with the current medical literature. The majority of PHF were treated nonoperatively in Belgium. 


\section{Declarations}

Conflict of Interest: Jan Dauwe, Carolin Danker, Michiel Herteleer, Kris Vanhaecht, Stefaan Nijs declare that they have no conflict of interest.

Funding: This work received no specific grant from any funding agency

Ethical approval: Not applicable

Acknowledgements: The authors would like to thank Dr. Jan Vandenbergen and the organization of NIHDI-

RIZIV-INAMI for facilitating data sharing for this research project. Also, Dr. Nicolas Flamey and Dr. Elizabeth Flesher for reading and correcting the manuscript grammatically. 


\section{References}

1. Organisation for Economic Co-operation and Development (OECD) [Internet]. Available from: https://stats.oecd.org/Index.aspx?ThemeTreeId=9

2. Woolf AD, Rheumatology EU of MSS of RB of. Healthcare services for those with musculoskeletal conditions: a rheumatology service. Recommendations of the European Union of Medical Specialists Section of Rheumatology/European Board of Rheumatology 2006. Ann Rheum Dis [Internet]. 2006/12/07. BMJ Group; 2007;66:293-301. Available from: https://www.ncbi.nlm.nih.gov/pubmed/17158137

3. Court-Brown CM, Caesar B. Epidemiology of adult fractures: A review. Injury. 2006.

4. Lanting B, MacDermid J, Drosdowech D, Faber KJ. Proximal humeral fractures: a systematic review of treatment modalities. J shoulder Elb Surg. United States; 2008;17:42-54.

5. Namdari S, Voleti PB, Mehta S. Evaluation of the osteoporotic proximal humeral fracture and strategies for structural augmentation during surgical treatment. J Shoulder Elb Surg [Internet]. Elsevier Ltd; 2012;21:1787_ 95. Available from: http://dx.doi.org/10.1016/j.jse.2012.04.003

6. Launonen AP, Lepola V, Saranko A, Flinkkilä T, Laitinen M, Mattila VM. Epidemiology of proximal humerus fractures. Arch Osteoporos [Internet]. 2015 [cited 2019 Jan 6];10:2. Available from: http://link.springer.com/10.1007/s11657-015-0209-4

7. Bergdahl C, Ekholm C, Wennergren D, Nilsson F, Möller M. Epidemiology and patho-anatomical pattern of 2,011 humeral fractures: data from the Swedish Fracture Register. BMC Musculoskelet Disord [Internet]. 2016 [cited 2019 Jan 6];17:159. Available from: http://bmcmusculoskeletdisord.biomedcentral.com/articles/10.1186/s12891-016-1009-8

8. Rose SH, Melton LJ 3rd, Morrey BF, Ilstrup DM, Riggs BL. Epidemiologic features of humeral fractures. Clin Orthop Relat Res. United States; 1982;24-30.

9. Court-Brown CM, Garg A, McQueen MM. The epidemiology of proximal humeral fractures. Acta Orthop [Internet]. 2001 [cited 2017 Mar 17];72:365-71. Available from:

http://www.ncbi.nlm.nih.gov/pubmed/11580125

10. Cummings S, Kelsey J, Nevitt M, O’Dowd K. Epidemiology of osteoporosis and osteoporotic fractures. Epidemiol Rev [Internet]. 1985;7:178-208. Available from:

https://doi.org/10.1093/oxfordjournals.epirev.a036281

11. Rosas S, Law TY, Kurowicki J, Formaini N, Kalandiak SP, Levy JC. Trends in surgical management of proximal humeral fractures in the Medicare population: a nationwide study of records from 2009 to 2012 . J 
shoulder Elb Surg [Internet]. 2016 [cited 2019 Jan 6];25:608-13. Available from:

https://linkinghub.elsevier.com/retrieve/pii/S1058274615004486

12. Hasty EK, Jernigan EW, Soo A, Varkey DT, Kamath G V. Trends in Surgical Management and Costs for Operative Treatment of Proximal Humerus Fractures in the Elderly. Orthopedics [Internet]. 2017 [cited 2019 Jan 6];40:e641-7. Available from: http://www.healio.com/doiresolver?doi=10.3928/01477447-20170411-03

13. Floyd SB, Campbell J, Chapman CG, Thigpen CA, Kissenberth MJ, Brooks JM. Geographic variation in the treatment of proximal humerus fracture : an update on surgery rates and treatment consensus. Journal of Orthopaedic Surgery and Research; 2019;2:1-11.

14. Hardeman F, Bollars P, Donnelly M, Bellemans J, Nijs S. Predictive factors for functional outcome and failure in angular stable osteosynthesis of the proximal humerus. Injury. 2012;43:153-8.

15. Bonnevialle N, Tournier C, Clavert P, Ohl X, Sirveaux F, Saragaglia D. Hemiarthroplasty versus reverse shoulder arthroplasty in 4-part displaced fractures of the proximal humerus: Multicenter retrospective study. Orthop Traumatol Surg Res [Internet]. 2016;102:569-73. Available from:

http://www.sciencedirect.com/science/article/pii/S1877056816300032

16. Aitken SA, Hutchison JD, McQueen MM, Court-Brown CM. The importance of epidemiological fracture data: injury epidemiology for the non-epidemiologist. Bone Joint J. England; 2014;96-B:863-7.

17. Herteleer M, Hoekstra H, Nijs S. Diagnosis and treatment of clavicular fractures in Belgium between 2006 and 2015. J shoulder Elb Surg. United States; 2018;27:1512-8.

18. Belgian Government. National Institute for Health and Disability Insurance (NIHDI-RIZIV-INAMI) [Internet]. Available from: https://www.riziv.fgov.be/n1/Paginas/default.aspx

19. STATBEL. Belgium in figures [Internet]. Available from:

https://statbel.fgov.be/en/themes/population/structure-population

20. Kim SH, Szabo RM, Marder RA. Epidemiology of humerus fractures in the United States: nationwide emergency department sample, 2008. Arthritis Care Res (Hoboken). United States; 2012;64:407-14.

21. Kristiansen B, Barfed G, Bredesen J, Erin-Madsen J, Grum B, Horsnaes MW, et al. Epidemiology of proximal humeral fractures. Popul (English Ed. 1987;

22. Katthagen JC, Huber M, Grabowski S, Ellwein A, Jensen G, Lill H. Failure and revision rates of proximal humeral fracture treatment with the use of a standardized treatment algorithm at a level-1 trauma center. $\mathrm{J}$

Orthop Traumatol [Internet]. 2017 [cited 2019 Jan 6];18:265-74. Available from:

http://link.springer.com/10.1007/s10195-017-0457-8 
23. Fu T, Xia C, Li Z, Wu H. Surgical versus conservative treatment for displaced proximal humeral fractures in elderly patients: a meta-analysis. Int J Clin Exp Med [Internet]. 2014 [cited 2018 Dec 25];7:4607-15. Available from: http://www.ncbi.nlm.nih.gov/pubmed/25663957

24. Iyengar JJ, Devcic Z, Sproul RC, Feeley BT. Nonoperative Treatment of Proximal Humerus Fractures: A Systematic Review. J Orthop Trauma [Internet]. 2011;25. Available from:

https://journals.lww.com/jorthotrauma/Fulltext/2011/10000/Nonoperative_Treatment_of_Proximal_Humerus.6.a $\operatorname{spx}$

25. Cuff DJ, Pupello DR. Comparison of Hemiarthroplasty and Reverse Shoulder Arthroplasty for the Treatment of Proximal Humeral Fractures in Elderly Patients. JBJS [Internet]. 2013;95. Available from: https://journals.lww.com/jbjsjournal/Fulltext/2013/11200/Comparison_of_Hemiarthroplasty_and_Reverse.9.asp $\mathrm{X}$ 